\title{
Non-linear modelling of the elliptical dome of the Sanctuary at Vicoforte
}

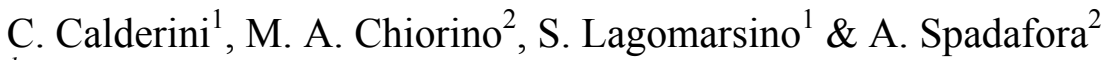 \\ ${ }^{I}$ Department of Civil, Environmental and Architectural Engineering, \\ University of Genoa, Italy \\ ${ }^{2}$ Department of Structural and Geotechnical Engineering, \\ Turin Polytechnic, Italy
}

\begin{abstract}
With its internal axes of 37.23 by $24.89 \mathrm{~m}$, the dome of the Sanctuary of Vicoforte, Italy, is the fifth biggest in the world in absolute term, and by far the largest elliptical dome ever built. The dome-drum system has suffered since the beginning from significant structural problems, partly due to soil settlements and arising from its bold structural configuration. This paper deals with the modelling strategies adopted in the assessment of the structural reliability of the monument, a project undertaken in recent years following the strengthening intervention operated in 1985 with the application of active tie-bars around the perimeter at the top of the drum. The structural behaviour of the construction was modelled according to two different approaches: limit analysis and finite element analysis (linear and non-linear). This paper presents the results obtained by non-linear constitutive models for the masonry.
\end{abstract}

Keywords: masonry elliptical dome, non-linear finite elements analysis.

\section{Introduction}

The Sanctuary of Vicoforte (Cuneo, Italy), is a building of great historical, architectural and structural significance, owing its fame primarily to the great masonry elliptical dome (Figures 1(a)-(b)), which is the biggest in the world of this shape in terms of overall dimensions (internal axes 37.23 by $24.89 \mathrm{~m}$ ).

Originally conceived by Duke Charles Emmanuel I of Savoy to serve as the mausoleum of the dynasty, the Sanctuary of Vicoforte began to be constructed in 1596, based on a project by architect Ascanio Vittozzi (1583-1615). Since the 
earliest stages of construction, the building was adversely affected by important differential settlements of the foundations, due to an unfortunate selection of the site. In 1615, when Vittozzi died, the construction had reached only the level of the impost of the big arches at the base of the drum. During the seventeenth century, construction works were resumed and dragged on for several years, reaching about mid height of the drum structure. In the early eighteenth century, works were entrusted to architect Francesco Gallo (1672-1750), who demolished the previous part of the drum, levelled its base because of excessive deformations, and erected a new slender drum with large window openings. The construction of the shallow baroque ribbed dome was started in 1731, when the monument had lost its original role as a royal family mausoleum, and was completed in less than a year. The Sanctuary was inaugurated in 1735, upon the completion of the lantern top [1].

The dome-drum system has suffered over the years from significant structural problems, partly due to further settlements of the building induced progressively by newly built masses, and, to a large extent, arising from the bold structural configuration of the dome-drum system itself (Figure 2).
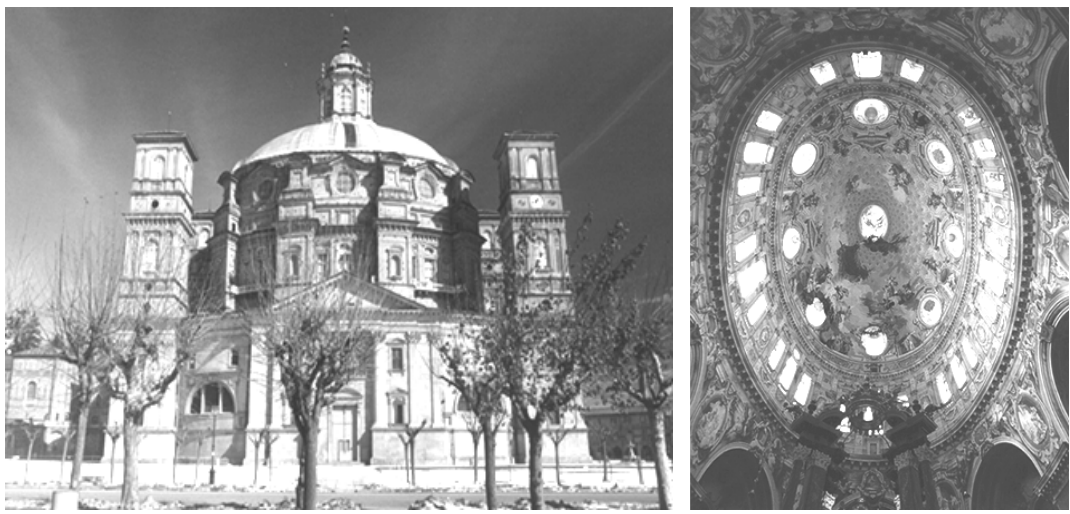

Figure 1: External and internal view of the Sanctuary.

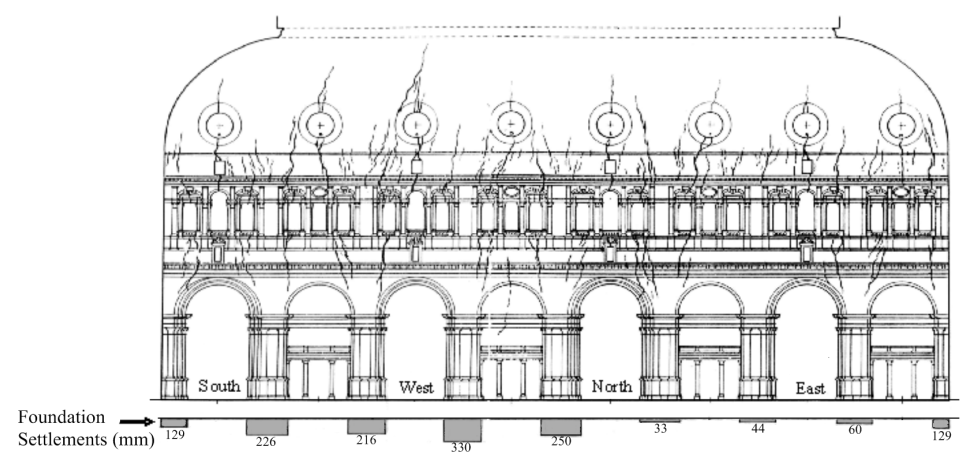

Figure 2: $\quad$ Crack distribution and total settlements along the perimeter [2]. 
In 1983, concerns over the severe settlement and cracking phenomena affecting the structure prompted the decision to undertake inspection, monitoring and strengthening interventions. After a survey and investigation campaign designed to acquire detailed data on the conditions of the foundations, the geotechnical aspects of the site, the geometry of the dome and the monument as a whole, and the mechanical parameters of the masonry, a strengthening system was put in place (1985-1987). It consisted of 56 active tie-bars placed within holes drilled in the masonry at the top of the drum along 14 tangents around the perimeter. A monitoring system was set up to measure strains, stresses and crack propagation, as well as stresses in the reinforcing tie-bars (re-tensioned in 1997).

In recent years, a thorough renovation of the monitoring system was carried out and a new research program was initiated in order to provide new advanced bases for the general plans for the preservation and the protection of the monument. The final goal of this research program is to define a model of the structure which, once integrated with monitoring results, might be able to describe the actual behaviour of the construction, predict its response to seismic actions and optimize future strengthening interventions.

Different types of analysis were performed on the monument: a limit state analysis of the dome-drum system; a linear elastic finite element analysis of the entire structure; an inelastic finite element analysis of the dome-drum system. The different modelling approaches adopted were prompted by a need to investigate different aspects of the behaviour of the structure [3]. Limit analysis was meant to arrive at an approximate evaluation of the overall safety of the dome-drum system (the zone of the structure where damages were most appreciable). It made it possible to describe the out-of-plane behaviour of the dome along its two main sections and to investigate the role of the annular tierods. The elastic finite elements analysis was aimed at describing the overall behaviour of the entire structure, recognizing the role of its structural elements and evaluating the entity of the principal stresses acting on its main sections. The inelastic finite elements analysis was aimed at giving a mechanical interpretation of the damage pattern of the dome-drum system, analysing both the gravity loads and settlements effects. The availability of a non-linear anisotropic constitutive law made it possible to analyse the role of the masonry pattern, evidencing the role of structural elements "hidden" in the masonry structure (relieving arches, oval arches, etc...). The paper presents only this latter approach.

\section{Knowledge of the monument}

Numerous investigations have been carried out on the Sanctuary of Vicoforte since 1930. However, due to the multiplicity of technicians and administrators involved in the conservation of the monument, the information stored in the curse the last decades was quite disorganized. Thus, in the research program underway, an effort was made not only to acquire new information, but also to collect and organize the data already available. In this paragraph, a concise report on the existing knowledge of the construction, useful for modelling and understanding its structural behaviour, is provided. 


\subsection{Description of the structure}

The drum-dome system is supported by eight huge masonry pillars (1) (Figure 3(c)), whose stiffness in the radial direction is increased by the radial walls separating the chapels of the church (2). A slender and transparent drum (3), of reduced thickness $(2.20 \mathrm{~m})$ and characterized by large triple windows (4), connects the dome to the underlying structures. The elliptical dome (5) has a thickness varying from $2.20 \mathrm{~m}$ at the impost to $1.27 \mathrm{~m}$ at the top. It is reinforced by eight ribs (6) on the extrados, radially arranged, at eight rather slender buttresses (7). Four of these buttresses, adjacent to the major axis of the oval, are hollow (one of them houses a helical stair) (Figure 3(d)). Eight oval openings (8), located between the buttresses, illuminate the interior of the dome. The dome is topped by a huge heavy sandstone lantern (9) and is surrounded by a tiburio (10). The space between the tiburio and the vault is filled with light-weight materials (sand and pottery shreds), while full masonry sections at the buttress locations ensure structural continuity. The top of the tiburio is connected to the dome by a reverse vault (11).

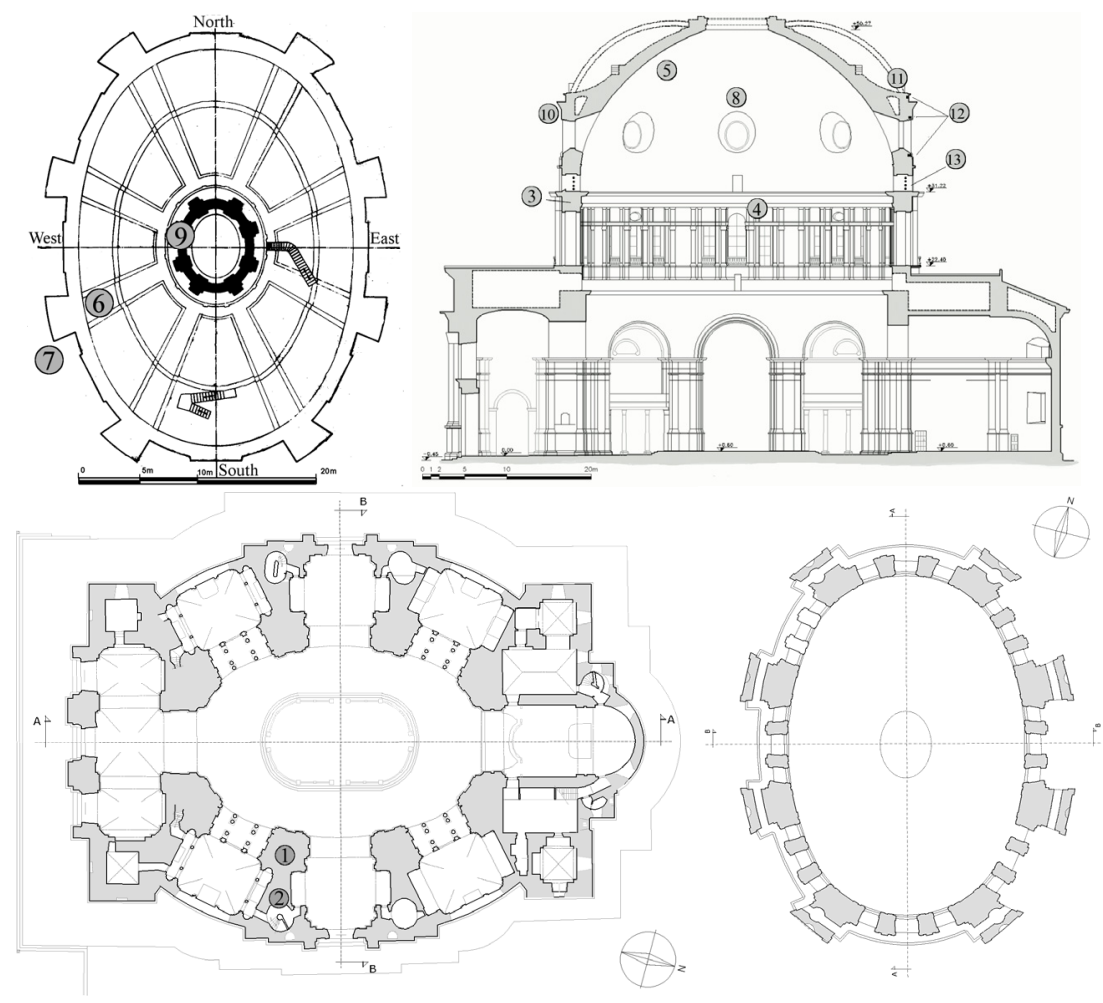

Figure 3: (a) Plan of the extrados of the dome. (b) Cross section along the major axis. (c) Plan of the Sanctuary (d) Plan of the drum. 
The dome is equipped with three sets of original iron annular ties (12) totaling a cross-sectional area of $140 \mathrm{~cm}^{2}$, positioned immediately above (2 ties $40 \times 70$ $\mathrm{mm}, 56 \mathrm{~cm}^{2}$ ) and below (1 tie 50x55 mm, $28 \mathrm{~cm}^{2}$ ) the oval windows, and at the top of the tiburio (2 ties $40 \times 70 \mathrm{~mm}, 56 \mathrm{~cm}^{2}$ ). The modern strengthening system located at the top of the drum along its perimeter (13) consists of four high strength steel Dywidag bars $\left(\mathrm{f}_{\mathrm{y}} \approx 1080 \mathrm{Mpa}, 32 \mathrm{~mm}\right.$ in diameter $)$ adding up to a cross-sectional area of $32 \mathrm{~cm}^{2}$ in each of the 14 tangential directions. The heads of the bars of two adjacent stretches are interconnected by steel frames. The bars were slightly tensioned at the beginning and re-tensioned in 1997 to compensate for stress losses. The structure of the dome is covered by a light wooden roof.

From historical records and direct inspections, it has been ascertained that the dome was constructed in general by arranging the mortar bed joints along the parallels and slanting them according to the curvature of the meridians. This masonry pattern is typical of domes. However, a detailed examination of the pattern on the extrados made it possible to identify two sets of relieving arches built in the thickness of the dome and the drum. The first set was built above the oval openings in the dome. The second set was built at an intermediate height between the triple windows of the drum and the dome impost. The first and second sets of relieving arches reduce the loads on the oval windows and the triple windows, respectively, by transferring them to the stiffer zones of the buttresses. The oval openings are built by means of thick oval masonry rings, present throughout the dome and the tiburio, while the two rectangular lateral openings of the triple windows are surmounted by stone architraves.

\subsection{Material characterisation}

In 1979, the following average data were obtained from compressive tests on masonry blocks taken from the building [4]: Young's modulus: $1500 \mathrm{MPa}$; compressive strength: $3 \mathrm{MPa}$.

In 2004, non-destructive tests were performed to evaluate the compressive strength and Young's modulus of mortar and bricks by means of a scratch tester (scratch width) and a Windsor Pin System (penetration resistance). These tests were flanked with compressive tests performed on small brick and mortar cylinders ( $\varnothing 33 \mathrm{~mm} \times 50 \mathrm{~mm}$ ) according to Japanese Standards JIS A 1108. Good correlations were found between the outcomes of two NDT tests and between the results of the latter and those of the compressive tests [5].

\subsection{Foundation ground}

Two main diagnostic investigations were performed to characterise foundation layers. The first campaign, carried out in 1976, consisted of 13 geotechnical surveys followed by laboratory tests on undisturbed soil samples. The surveys covered a vast area, inside and outside the Sanctuary, and were accompanied by the drilling of 29 bore holes through the foundations at the base of the masonry structure. The second campaign, carried out in 2004, coincided with the installation of the 3 electrical piezometric cells equipping the new monitoring system. It included 4 geotechnical surveys, each of which collected 5-6 
undisturbed soil samples that were subjected to tests; 2 cross-hole geophysical seismic tests were conducted in the bore holes to determine the velocity profiles of shear and compressive waves ( $\mathrm{S}$ and $\mathrm{P}$ waves) in stratified media.

As revealed by these investigations, a bedrock layer of marl slanted in the south-west direction (dip angle $5^{\circ}-6^{\circ}$ ), whose upper surface is generally weathered to a depth ranging from ca $20 \mathrm{~cm}$ to a maximum of just over $1 \mathrm{~m}$, is surmounted by a more recent formation of a fine-grained deposit of fluvial origin, with some old manmade filling in the upper part. This formation, mainly consisting of a clayey-silt layer with a low sand content, in lens form at some points, is about 5 to $10 \mathrm{~m}$ thick on the west side of the monument, and virtually disappears on the east side. Therefore, the east side of the monument is mostly founded directly on bedrock, whereas the foundation structures in the south-west zone of the monument, especially those of the pillars supporting the dome-drum system, rest on a silt-clay layer reaching a maximum thickness of $3 \mathrm{~m}$.

\subsection{Damage assessment and monitoring}

The Sanctuary of Vicoforte is affected by a widespread system of cracks (Figure 2) encompassing various zones of the structure. Two zones, in particular, cause concern: the zone of the dome-drum system affected by the presence of triple windows in the drum and oval openings in the dome, and the zone at the base of the buttresses. The former displays a finely spaced network of cracks running in the sub-vertical meridian direction, mostly concentrated in the masonry portion just above the impost of the dome with greater density next to the buttresses. The cracks become thicker and bigger in the proximity of the openings and tend to propagate all the way across between the upper and the lower series of openings. At the level of the dome impost we find 84 cracks adding up to a total width of $416 \mathrm{~mm}$. The main cracks, located along the axis of the oval openings of the dome, propagate upward towards the summit of the dome. The crack to the west is the biggest, with a maximum width of $48 \mathrm{~mm}$, and it almost reaches the closing ring of the dome. The second biggest crack is located to the north. The meridional cracks propagate downward beneath the drum, evidencing and confining load paths converging towards the main base pillars. The second zone of interest, at the base of the buttresses, displays diagonal cracks due to shear stresses induced by the radial thrusting action of the dome. Wider and longer cracks are observed in the two couples of hollow buttresses situated to the north and to the south, while in all the buttresses crack width becomes particularly large just above the vertical openings, causing some concern about possible effects in terms of local damages to the masonry texture.

From the historical records of the Sanctuary, it has been determined that cracking phenomena began to occur already in the lower part of the monument very early, during the initial stages of construction, before the erection of the new drum and the dome, basically as a consequence of the settlements of the foundations. The development of the crack pattern described above was particularly significant soon after the construction of the dome-drum system. Visual examinations performed over the years confirmed an increase in the damage pattern throughout the entire history of the structure. 
The damage evolution of the monument has been instrumentally controlled since 1983, with a monitoring system installed during the undertaken strengthening works. Between 2001 and 2004, the general architecture of the monitoring system was improved by adopting a technologically upgraded version of the instrumentation. The configuration of the monitoring system makes it possible to assess the evolution of the crack network and the efficiency of the strengthening system. The instruments used can be classified into two groups, i.e., tools for the measurement of displacements, strains, cracks and states of stress in the structure, and tools for measuring boundary and ambient conditions.

From a comparison between current monitoring data with those recorded before the 1985-1997 strengthening intervention, it seems clear that this intervention was effective.

\section{Non-linear analysis of the dome-drum system}

The inelastic finite element model of the dome-drum system (Figure 4) is made of shell elements (the vault was modelled by defining a mean surface). Each buttress was modelled with three rigidly connected layers of shells of appropriate
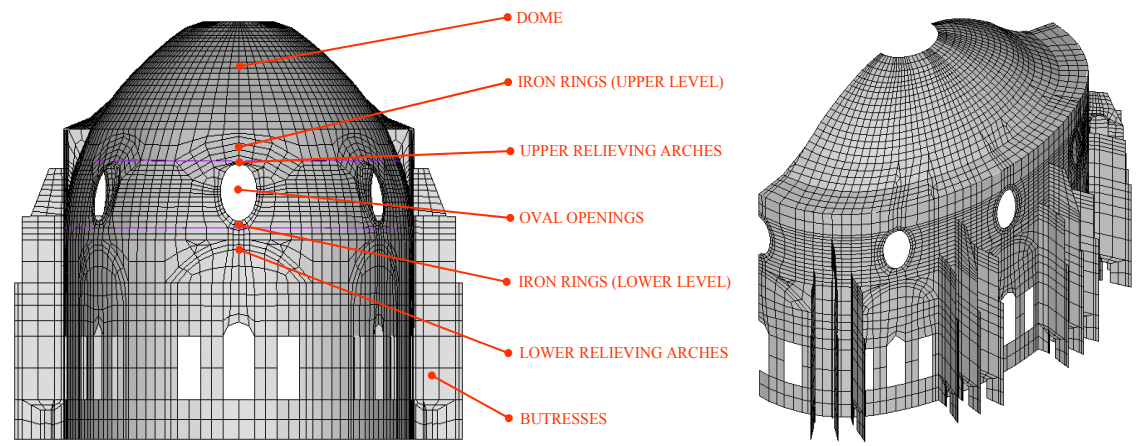

Figure 4: $\quad$ FEM model of the dome-drum system with shell elements.

thickness to simulate with sufficient approximation the inertia and the weight of the actual structure. The original strengthening rings were modelled by means of beam elements, connected to the shell nodes so as to ensure that the lengths of the ties would be approximately the same as in the original elements. The effects of the filling material between the tiburio and the vault were not taken into account, as it proved impossible to determine its characteristics in all the areas where it was present. The lantern was not included in the model, but it was analysed separately in order to define the loads that it transfers to the dome. These loads were then included in the finite element model in terms of distributed forces applied to the top masonry ring of the dome. In order to describe the masonry pattern of the structure, the element reference system was rotated according to the actual orientation of mortar joints. 
Horizontal restraints were placed at the base of the model, in order to prevent translation movements in either direction at the four buttresses adjacent to the major axis. This was inferred from the 3D solid linear elastic analysis performed on the entire structure of the Sanctuary, which revealed that in those zones horizontal displacements were negligible [6].

The constitutive law employed is based on a micromechanical approach [7]. The plane stress hypothesis is assumed. Masonry is considered as a composite material, made up of periodic sets of blocks connected by mortar joints. Mortar bed joints are assumed to be mechanically resistant (tensile strength and cohesion); moreover, friction at the mortar-block interface is considered. Mortar head joints are regarded as geometrical discontinuities; their mechanical behaviour is neglected. The masonry pattern is described by means of a single summary parameter, the angle of interlocking, i.e., the ratio between block width and block height. Constitutive equations consider the non-linear stress-strain relationship in term of mean stresses and mean strains. The latter are produced by an elastic strain contribution, associated with a homogenized elastic continuum, and by an inelastic strain contribution depending on damage. Different in-plane damage mechanisms are considered as concerns both the mortar joints and the blocks. Considering the full set of possible damage mechanisms affecting the joints, a hemisymmetric condition of the inelastic strains in the mortar bed joints is imposed. Damage evolution is described by means of an energetic approach (Rough-Curve approach). Moreover, the hysteretic behaviour of the masonry under cyclic loads is described by using a Coulomb-type friction law for the mortar bed joints. In particular, two damage variables are considered for hemisymmetric sets of mortar bed joints. This choice enables the model to describe the inelastic strains in the mortar head joints in terms of the difference between the tangential inelastic strains in the two sets of mortar bed joints. A specific condition is imposed in order to avoid the interpenetration of head joints. The constitutive equations are implemented in a general-purpose finite element code [8]. The procedure for the integration of the constitutive equations in the finite load step has been developed based on a description involving five internal variables which evolve during the incremental analysis. The Newton-Raphson method is adopted for the solution. In particular, the model was implemented in 4-node non-linear shell elements with transverse shear strain capability. Such elements have five integration points through the thickness. This feature makes it possible to describe the behaviour of the walls by means of series of layers subjected to in-plane mechanisms; thus, a description of their out-of-plane behaviour can be obtained. The adoption of a non-linear anisotropic constitutive law, based on both friction and cohesive mechanisms, made it possible to describe the complex masonry pattern characterizing the structure, emphasizing on the one hand the role of the dome pattern, the relieving arches and the oval openings, and, on the other hand the effects of friction on the resistant mechanisms of the structure.

The discretization of such a massive structure (dome thickness $>2 \mathrm{~m}$ ) with shell elements prompted the need to verify the reliability of the solution for increasingly coarser meshes. Convergence analyses, as well as calibrations with 
the solid model, showed that the solution does not become worse for shell width to thickness ratios smaller than 1 . Even though the quality of the numerical solution was assessed, the choice of shell elements (unavoidable in view of the complex constitutive law adopted) surely determined a strong simplification of the structure, leading to the loss of a wealth of information about its out-of-plane resistant mechanisms.

The mechanical parameters adopted in the model are summarized in Table 1. So far, limited experimental tests have been carried out on the materials making up the structure. Except for the compressive strength of the masonry and Young's modulus, $E_{y}$ [4], all the parameters have been defined qualitatively by considering the values typically associated with historic masonry [9]. It has been assessed through a set of non-linear analyses that, in a reasonable range of parameter values, the response of the structure is not qualitatively influenced by the variability of the parameters.

Table 1: $\quad$ Masonry material parameters assumed in FEM analysis.

\begin{tabular}{|c|c|}
\hline Homogenized normal elastic modulus $E_{x}$ & $2.010^{3} \mathrm{MPa}$ \\
\hline Homogenized normal elastic modulus $E_{y}$ & $1.510^{3} \mathrm{MPa}$ \\
\hline Homogenized tangential elastic modulus $G_{x y}$ & $8.010^{2} \mathrm{MPa}$ \\
\hline Poisson coefficient $v$ & 0.2 \\
\hline Friction coefficient $\mu$ & 0.6 \\
\hline Tensile strength of mortar joints $\sigma_{m r}$ & $0.05 \mathrm{MPa}$ \\
\hline Cohesion of mortar joints $\tau_{m r}$ & $0.1 \mathrm{MPa}$ \\
\hline Compressive strength of the masonry $\sigma_{M r}$ & $3 \mathrm{MPa}$ \\
\hline Tensile strength of blocks $\sigma_{b r}$ & $0.5 \mathrm{MPa}$ \\
\hline Shear strength of blocks $\tau_{b r}$ & $2 \mathrm{MPa}$ \\
\hline Ratio between the elastic and inelastic shear strain at failure in mortar joints & 2 \\
\hline Ratio between elastic and inelastic strain in compression at failure & 1.5 \\
\hline Softening coefficient of mortar joints $\beta_{m}$ & 0.2 \\
\hline Softening coefficient of blocks $\beta_{b}$ & 0.2 \\
\hline Interlocking ratio $\varphi$ & 4 \\
\hline
\end{tabular}

Two different analyses were performed. In the first, only gravity loads were considered. In the second, besides the gravity loads, the deformations at the drum base due to the settlements of the foundations and the deformations of the underlying structure were considered. The deformations at the drum base were introduced as imposed vertical displacements; their values were obtained from a reasonable estimate of the amount of differential settlements that occurred after the completion of the dome with reference to a geometric levelling of the base cornice [2]. This choice is justified by the fact that, from the historical records [1], it appears that the base impost was reconstructed and levelled before building the drum and the dome.

The use of an anisotropic damage model requires appropriate tools to express the results, in particular in the case of a 3D structure. In fact, the use of different local coordinate systems for the elements (used for the description of the different masonry patterns within the structure) leads to a difficult interpretation of the local inelastic strains. In the following description of the results obtained, they will be expressed in terms of: maximum principal inelastic strains, in order 
to consider only positive strains (crack openings) independently of the local reference system; strains in the local reference systems, along the two directions parallel and orthogonal to the mortar bed joints. For the interpretation of the results, the hypothesis of smeared cracks should also be taken in account. In fact, in the model, the inelastic strains are diffused over a certain area and there is no direct evidence of cracks.

The analysis of the structure under gravity loads pointed out some intrinsic weaknesses of the structure: a) the damage pattern is quite symmetric; b) the highest, and broadly diffused, principal inelastic strains are at the oval openings and the relieving arches; c) inelastic strains are present above and below the openings at the base of the drum.

The meaning of such a damage state can be grasped by comparing the principal strains with the local strains. Figure 5 shows the local inelastic strains, in the three plane components of the shells. Only strains in those elements in which failure has been reached (at least one integration point) are represented.

The strains parallel to the bed joints are localized:

- at the base of the dome, below the arch rings of the oval openings;

- above the arch ring of the oval openings;

- at the springings of the relieving arches;

- below the openings at the base of the drum;

- above the central openings (of each span) at the base of the drum.

\begin{tabular}{|c|c|c|}
\hline Strains parallel to bed joints & Strains orthogonal to bed joints \\
\hline External view & Internal view & External view \\
\hline
\end{tabular}

Figure 5: Non-linear analysis under gravity loads. Inelastic strains in the elements local coordinate system (West side).

On the basis of the foregoing observations, it can be observed that the inelastic strains parallel to the mortar bed joints are strongly associated with friction. Cohesion being very low, their occurrence depends mainly on the ratio between the circumferential tensile stresses and the rate of compression on the bed joints.

The strains orthogonal to the bed joints are localized:

- above and below the arch rings of the oval openings;

- at the crowns of the two sets of relieving arches;

- above the openings at the base of the drum. 
The inelastic shear strains substantially confirm the previous observations, in particular those regarding the relieving arches. Because of the change in orientation of the mortar bed joints, the vertical compressive stresses transmitted by the upper parts of the structure become local shear stresses in the arches.

In general, it can be stated that the inelastic strain pattern obtained through the non-linear analysis is compatible with the crack pattern observed in the real structure. In particular, a good correspondence can be found between the cracks above and below the openings. Moreover, the model points out the increase in damage at the minor axis of the dome. The most critical point concerns the relieving arches; in fact, in the real structure there is no conclusive evidence of damage at their backs.

\section{Conclusions}

From the results obtained with the different mathematical models, the following conclusions can be drawn:

- The primary causes of the structural damage that has affected the dome-drum system of the Sanctuary of Vicoforte are its daring structural configuration and the differential settlements of the foundations that occurred after the completion of the dome. The first cause generated a pattern of meridian cracks, distributed over the entire perimeter, accompanied by diagonal shear cracks in the buttresses; the second cause resulted in more significant damages, enhancing the cracks due to the first cause in the zones most affected by differential settlements.

- Albeit not exhaustive and despite some interpretation limits, the non-linear modelling of the dome-drum system made it possible to identify some significant aspects of the behaviour of the structure, in particular the role of the relieving arches present in the surfaces of the vault and the drum. These relieving arches, built in order to convey the loads towards the buttresses, and hence to relieve the surfaces of the drum perforated by the voids of the triple windows, turn out to be, to some extent, elements that tend to weaken the structure. In fact, on one hand they reduce the compressive loads acting on the bed mortar joints, thereby attenuating the favourable effects of friction. Similar remarks can be made regarding the rings and the architraves defining the openings themselves; however, in this case, the architect could make no other choice, since the creation of an opening in a masonry structure always calls for a relieving system (whether an arch or an architrave).

- Geotechnical surveys describe a foundation soil so well consolidated that, being hydrogeological conditions stable, the occurrence of further settlements of the foundations, and hence further damage to masonry, can be ruled out.

- Both numerical analyses and data obtained from the diagnostic investigations and the monitoring system indicate that the structure is basically stable.

The analyses completed so far supply a partial contribution to an understanding of the structure. A more exhaustive interpretation of the structural behaviour of the construction may arise solely from the interaction of different modelling strategies (3D linear analysis, limit analysis, non-linear analysis using 
different constitutive laws), from a better knowledge of the structure (assessment of the structural integrity of the ancient cerclage and identification of the inner make up of the masonry of the dome and drum) and from modelling soil structure-interaction, with due account for the influence of historical construction phases. These are the basic steps of the research program currently under way. Dynamic monitoring, presently under study and to be implemented soon, will offer valuable opportunities for the updating and validation of current and future models, as well as for the seismic assessment of the monument.

The combination of these results with the data obtained from diagnostic investigations and long-term monitoring will make it possible to formulate hypotheses and outline conceivable scenarios and strategies for the structural preservation of the monument. In particular the safety of the monument with regards to seismic actions will be investigated, according to the recommendations recently issued by the Italian Ministry of Cultural Heritage [10].

\section{References}

[1] Vacchetta G., New artistic history of the Sanctuary of the Virgin of Mondovì at Vico (in Italian) Cuneo: Società per gli Studi Storici Archeologici ed Artistici della Provincia di Cuneo, 1984.

[2] Garro, M., The Sanctuary of Vicoforte: strengthening and rehabilitation works (in Italian). Cuneo: Technical report, 1962.

[3] Chiorino M.A., Spadafora A., Calderini C., Lagomarsino S., Modeling strategies for the world's largest elliptical dome at Vicoforte. International Journal of Architectural Heritage. vol. 2, pp. 274-303, 2008.

[4] Barosso L., The dome-drum structure of the Sanctuary of Vicoforte: materials and construction techniques (in Italian). Turin: Atti e Rassegna Tecnica della Società degli Ingegneri e degli Architetti di Torino, 1979.

[5] Aoki, T., Komiyama, T., Tanigawa, Y., Hatanaka, S., Yuasa, N., Hamasaki, H., Chiorino, M. A. and Roccati, R., Non-destructive Testing of the Sanctuary of Vicoforte. Proc. of 13th International Brick and Block Masonry Conference, vol.4, 1109-1118. Amsterdam, 2004.

[6] Chiorino, M.A., Roccati, R., D’Addato, C., Aoki, T., Calderini, C. and Spadafora, A., Monitoring and modelling strategies for the world's largest elliptical dome at Vicoforte, Proc. V Int. Conf. on Structural Analysis of Historical Constructions, vol. 2. 1167-1176. New Delhi, 2006.

[7] Calderini, C. and Lagomarsino, S., Continuum model for in-plane anisotropic inelastic behavior of masonry. Journal of Structural Engineering ASCE, Vol. 134, No. 2, pp. 209-220, 2008.

[8] ANSYS User's Manual, Revision 8.0, ANSYS Inc., Houston, USA, 2003.

[9] Binda, L., The knowledge of materials and construction techniques: an important step for the evaluation of masonry structures. Proc. of the $2^{\text {nd }}$ Joint USA/Italy Workshop "Learning from practice: Damage assessment for design decision and effectiveness of techniques”, 3-27. Rome: CNR, 1996.

[10] Guidelines for evaluation and mitigation of seismic risk to cultural heritage (Ed.: Laura Moro), Gangemi Ed., ISBN 978-88-492-1269-3, 2007. 